\title{
Regulatory effect between HMGA2 and the Wnt/ß-catenin signaling pathway in the carcinogenesis of sporadic colorectal tubular adenoma
}

\author{
DAN LI, YANAN CAO, JUAN WANG, HAIYAN YANG, WEINA LIU, JINFENG CUI and WENXIN WU
}

Department of Pathology, The Second Hospital of Hebei Medical University, Shijiazhuang, Hebei 050000, P.R. China

Received May 14, 2021; Accepted August 31, 2021

DOI: 10.3892/ol.2021.13110

\begin{abstract}
Due to the high incidence of colorectal cancer worldwide, the underlying molecular mechanisms have been extensively investigated. The $\mathrm{Wnt} / \beta$-catenin signaling pathway plays a key role in the carcinogenesis of colorectal adenoma. In addition, the high mobility group AT-hook 2 (HMGA2) protein, which is involved in several biological processes, such as proliferation, differentiation, transformation and metastasis, is expressed at significantly high levels in colorectal cancer tissues compared with adjacent normal tissues. Currently, the role of HMGA2 in the carcinogenesis of sporadic colorectal tubular adenoma remains unclear. The downstream Wnt/ $/$-catenin signaling molecule, T-cell factor/lymphoid enhancing factor (TCF/LEF), shares a similar domain with HMGA2, which enhances $\beta$-catenin transcriptional activity and TCF/LEF binding. Thus, the present study investigated the association between HMGA2 and the Wnt/ $\beta$-catenin signaling pathway, and their role in the carcinogenesis of sporadic colorectal tubular adenoma via immunohistochemistry, siRNA, quantitative PCR and western blot analyses. The results demonstrated that the positive rate of HMGA2 expression gradually increased during tumor progression. Furthermore, HMGA2 expression was positively correlated with $\mathrm{Wnt} / \beta$-catenin signaling protein expression [Wnt, $\beta$-catenin, cyclin-dependent kinase 4 (CDK4) and cyclin D1], suggesting its involvement in the carcinogenesis of sporadic colorectal tubular adenoma and its potential to synergistically interact with the $\mathrm{Wnt} / \beta$-catenin signaling pathway.
\end{abstract}

Correspondence to: Dr Wenxin Wu, Department of Pathology, The Second Hospital of Hebei Medical University, 215 West Heping Road, Shijiazhuang, Hebei 050000, P.R. China

E-mail:wwx112@126.com

Abbreviations: HMGA2, high mobility group AT-hook 2; TCF, T-cell factor; LEF, lymphoid enhancing factor; NCM, normal colorectal mucosa; SCTA-D, sporadic colorectal tubular adenomas with dysplasia; SCTA-Ca, sporadic colorectal tubular adenomas with cancerous changes; PBS, phosphate-buffered saline

Key words: HMGA2, Wnt/ $\beta$-catenin, colorectal adenoma, carcinogenesis
HMGA2 knockdown in the human colorectal cancer cell line, HCT 116 decreased $\beta$-catenin expression and its downstream targets, CDK4 and cyclin D1. Furthermore, silencing of Wnt or $\beta$-catenin decreased HMGA2 expression. Taken together, the results of the present study suggest the coordinated regulation of HMGA2 and the Wnt/ $\beta$-catenin signaling pathway in the carcinogenesis of sporadic colorectal tubular adenoma.

\section{Introduction}

Colorectal adenoma is a relatively common benign lesion with potential for carcinogenesis (1-3). Its incidence increases with age after 30 years, and it is common in Chinese people $>40$ years ( $40-50 \%)$, including sporadic and familial cases (4). Currently, four types of colorectal adenoma have been defined based on histology, tubular adenomas, villous adenomas, tubulovillous adenomas and serrated adenomas, whereby tubular adenomas are the most common subtype (5).

Colorectal adenoma is associated with colorectal cancer, and at least $80 \%$ of colorectal carcinomas undergo neoplastic progression via the normal epithelium-adenoma-adenocarcinoma sequence (6). Cancer-associated mortality can be reduced by early detection and removing clinically significant adenomas (7). Thus, it is important to understand the progression from adenomas to colorectal carcinomas to facilitate the development of novel treatment strategies and improve clinical outcomes. However, most studies investigating the carcinogenesis of colorectal adenomas have focused on villous adenoma and familial adenomatous polyposis, which have the highest rates of carcinogenesis $(8,9)$. Only a few studies have investigated sporadic tubular adenoma, which has the highest clinical incidence $(10,11)$. Thus, systematic and comprehensive investigations of the molecular mechanisms of sporadic colorectal tubular adenoma carcinogenesis, including evaluations of its etiology and pathogenesis, are required.

Carcinogenesis is a complex process involving multiple genes and genetic interactions, such as Wnt, Ras and TGF- $\beta$ signaling pathways $(12,13)$. The $\mathrm{Wnt} / \beta$-catenin signaling pathway plays a key role in the carcinogenesis of colorectal adenoma (14). Previous studies have reported the nuclear accumulation of $\beta$-catenin early and consistently in the adenoma-carcinoma sequence of colorectal cancers $(15,16)$. The regulation of transcription factors in the Wnt signaling pathway plays an important role in the 
carcinogenesis of adenoma $(17,18)$. In addition, high mobility group AT-hook 2 (HMGA2), an architectural transcription factor that regulates several genes, such as E2F1 and T-cell factor/lymphoid enhancing factor (TCF/LEF) $(19,20)$, is considered a potential tumor marker for several human malignant neoplasms, including lung (21-23), breast $(24,25)$, gastric $(26,27)$ and colorectal (28) cancers. Previous studies have also reported shared regulatory mechanisms between HNGA2 and $\beta$-catenin (29,30). However, whether HMGA2 is involved in the Wnt/ $\beta$-catenin pathway-mediated carcinogenesis of adenomas remains unclear.

The present study aimed to investigate HMGA2 expression and its clinical significance in the carcinogenesis of sporadic colorectal tubular adenoma. In addition, the association between HMGA2 and the Wnt/ $\beta$-catenin signaling pathway in colorectal cancer cells was assessed. Understanding the molecular mechanisms by which HMGA2 functions in the carcinogenesis of colorectal adenoma may enable the development of effective targeted therapies for colorectal cancer.

\section{Materials and methods}

Human tissue samples. A total of 263 formalin-fixed and paraffin-embedded colorectal tissue samples were obtained by surgical resection and biopsy from the Department of Pathology at the Second Hospital of Hebei Medical University (Shijiazhuang, China) between December 2010 and May 2013. The patients included 141 men and 122 women (mean age, 53.0 years; age range, 23-84 years). Of these samples, 105 were sporadic colorectal tubular adenomas with cancerous changes (SCTA-Ca) and 121 were SCTA with different dysplasia (SCTA-D), which included 46 adenomas with low-grade dysplasia, 44 adenomas with moderate-grade dysplasia and 31 adenomas with high-grade dysplasia. According to pathological morphology, SCTA-D was divided into three grades, which were low-grade dysplasia, moderate-grade dysplasia and high-grade dysplasia. Low-grade dysplasia showed that the number of goblet cells in the glandular duct decreased, the cells were arranged in multiple layers, and the nucleus was pen rod-shaped, located at the base of epithelial cells, with a height less than 1/2 of that of epithelial cells. Moderate-grade dysplasia showed that the nuclei were arranged in multiple layers, accounting for $2 / 3$ of the height of epithelial cells. The glandular tubes were elongated and distorted, with different sizes. High-grade dysplasia showed obvious enlargement of nuclei, disappearance of polarity, rare or disappearance of goblet cells, obvious sprouting of glandular branches, and common wall and back-to-back phenomena. A total of 37 normal colorectal mucosa (NCM) tissues $(5 \mathrm{~cm}$ from the corresponding cancer or adenoma tissues) were used as the control group. All TNM stage data were obtained from the clinical and pathological diagnoses (31). None of the patients had received chemotherapy or radiotherapy prior to surgery. Familial colonic polyposis and juvenile polyposis should be excluded from the medical history and serrated and villous colorectal adenomas should be excluded from the histopathological type. All pathological sections were examined and verified by two senior pathologists. In subsequent experiments, the tissue sections were stored at room temperature. The present study was approved by the Research Ethics Committee of the
Second Hospital of Hebei Medical University (Shijiazhuang, China; approval no. 2014057) and written informed consent was provided by all participants prior to the study start.

Immunohistochemistry (IHC) analysis. Histological sections (4- $\mu \mathrm{m}$ thick) were prepared from the $4 \%$ formalin-fixed paraffin-embedded tissue sections for $48 \mathrm{~h}$ at room temperature. Following deparaffinization, antigen retrieval was performed with citrate buffer for $15 \mathrm{~min}$ at $120^{\circ} \mathrm{C}$. Endogenous peroxidase activity was blocked using $3 \%$ hydrogen peroxide in methanol for $10 \mathrm{~min}$ at room temperature. Goat serum (OriGene Technologies, Inc.) was used for blocking non-specific binding sites for 1-2 $\mathrm{h}$ at room temperature. Slides were then incubated with primary antibodies against HMGA2 (1:300 dilution; GTX100519; GeneTex,Irvine), Wnt (1:200 dilution; FNab09517; FineTest,Wuhan Fine Biotech Co.); $\beta$-catenin (1:50 dilution; AF6266; Affinity Biosciences), cyclin-dependent kinase 4 (CDK4, 1:200 dilution; ab137675; Abcam) and Cyclin D1 (1:100 dilution; ab16663; Abcam) overnight at $4^{\circ} \mathrm{C}$. As a negative control, the primary antibody was omitted. After washing three times with PBS for $5 \mathrm{~min}$, a Biotin-Streptavidin HRP Detection system (working solution; OriGene Technologies, Inc.; SP-9000/9001/9002) was used for detection of the antigen-antibody complex. Subsequently, tissues sections were stained using the Elivision ${ }^{\mathrm{TM}}$ Plus kit (Fuzhou Maixin Biotech Co., Ltd.), according to the manufacturer's instructions. Counterstaining was performed using hematoxylin for $2 \mathrm{~min}$ at room temperature. Parallel staining was performed in the absence of a primary antibody as the negative control (NC) for $2 \mathrm{~min}$ at room temperature.

Immunohistochemical staining evaluation and immunohistochemical score. The immunoreactivity of stained tissue sections was independently scored by two experienced pathologists using an Olympus BX53 light microscope (Olympus Corporation) in at least three fields of view at x200 magnification, who were blinded to the clinicopathological characteristics and clinical outcomes of the patients. The pairs of scores were compared, and any discrepancies were resolved through re-examination of the stains by both pathologists to achieve a consensus score.

HMGA2 was identified as brown nuclear staining. Immunoreactivity to HMGA2 was scored semi-quantitatively by evaluating both the percentage of positive cells and staining intensity. A percentage-based approach was used to estimate the proportion of positively stained tumor cells as follows: 0 , none; $1,<1 \% ; 2,1-10 \% ; 3,11-33 \% ; 4,34-66 \%$ and $5,67-100 \%$. Average estimated intensity of staining in positive cells was scored as follows: 0 , no signal; 1 , weak; 2 , intermediate and 3, strong. The final score was calculated as the sum of the proportion and intensity scores (32).

Wnt was identified as brown cytoplasmic staining. With regards to Wnt, the percentage of positive cells was scored as follows: $0,0 \% ; 1,1-10 \% ; 2,11-50 \% ; 3,51-70 \%$ and $4,71-100 \%$. The intensity of staining was scored as follows: 0 , no signal; 1 , weak; 2 , moderate and 3 , strong. The immunoreactivity score was calculated as the sum of the percentage of positive cells and the staining intensity scores (33).

Only nuclear staining is considered positive for $\beta$-catenin. Staining intensity was scored as follows: 0 , negative; 1 , weak; 
2 , moderate and 3 , strong. The percentages of positive nuclei were recorded in $10 \%$ increment from $0-100 \%$. A histological score was calculated as the sum of the staining intensity and percentage scores (34).

CDK4 was identified as brown nuclear staining. With regards to CDK4, the percentage of positive tumor cells was scored as follows: $0, \leq 5 \% ; 1,6-25 \% ; 2,26-50 \% ; 3,51-75 \%$ and $4, \geq 76 \%$. Staining intensity was scored as follows: 0 , no color; 1 , pale yellow; 2 , tan and 3 , brown. The final score was calculated as the sum of the percentage of positive cells and intensity scores (35).

Cyclin D1 was identified as brown nuclear staining. With regards to Cyclin D1, staining intensity in both the cytoplasm and nuclei were scored and stratified as follows: grade 0 , no staining or negative; grade 1, light yellow or weak positive; grade 2, yellow or moderate positive and grade 3, yellow/brown or strong positive, respectively. Staining score was defined as follows: score $0, \leq 5 \%$; score $1,6-25 \%$; score $2,26-50 \%$; score $3,51-75 \%$ and score $4,>76 \%$ of cells were stained. The final immunoreactivity score was calculated as the sum of the grade and staining scores (36).

Cell culture. The human colorectal cancer cell line, HCT 116 was purchased from The Cell Bank of Type Culture Collection of The Chinese Academy of Sciences. HCT 116 cells were maintained in RPMI-1640 (Hyclone; Cytiva) supplemented with $10 \%$ fetal bovine serum (FBS, Hyclone; Cytiva), at $37^{\circ} \mathrm{C}$ in a humidified incubator with $95 \%$ air and $5 \% \mathrm{CO}_{2}$. Cells cultured to $80 \%$ confluence were passaged by trypsinization.

Small interfering (si)RNA transient transfection. SiRNAs against HMGA2, Wnt, $\beta$-catenin and NC were synthesized by Shanghai GenePharma Co., Ltd. The following sequences were used: siRNA-HMGA2 forward, 5'-GGACAAUCUACUACC AAGATT-3' and reverse, 5'-UCUUGGUAGUAGAUUGUC CTT-3'; siRNA-Wnt forward, 5'-GCGCAUUUGUGGAUG CAAATT-3' and reverse, 5'-UUUGCAUCCACAAAUGCG CTT-3'; siRNA- $\beta$-catenin forward, 5'-GUCCUGUAUGAG UGGGAACTT-3' and reverse, 5'-GUUCCCACUCAUACA GGACTT-3'; and siRNA-NC forward, 5'-GGACAACUCACU ACCAAGATT-3' and reverse, 5'-UCUUGGUAGUAGAUU GUCCTT-3'. HCT 116 cells were seeded into 6-well plates at a density of $1 \times 10^{5}$ cells/well in DMEM (Gibco; Thermo Fisher Scientific, Inc.). Cells were reverse-transfected with siRNA-NC or siRNAs targeting HMGA2, Wnt and $\beta$-catenin at a concentration of 100 pmol using Lipofectamine ${ }^{\circledR} 2000$ reagent (Invitrogen; Thermo Fisher Scientific, Inc.) for $2 \mathrm{~h}$ at $37^{\circ} \mathrm{C}$, according to the manufacturer's instructions. Cell media was supplemented with $1 \%$ FBS $24 \mathrm{~h}$ post-transfection and cells were incubated for an additional $6 \mathrm{~h}$. Following incubation, the transfection complex was replaced with fresh cell media supplemented with $10 \%$ FBS. Cells were harvested, and transfection efficiency was assessed via reverse transcription-quantitative (RT-q)PCR and western blot analyses $48 \mathrm{~h}$ post-transfection. The experiments was repeated at least four times.

$R T$ - $q P C R$. Total RNA was extracted from HCT 116 cells using TRIzol ${ }^{\circledR}$ reagent (Invitrogen; Thermo Fisher Scientific, Inc.), according to the manufacturer's instructions. RNA concentration and integrity were determined via spectrophotometry (NanoDrop, ND-1000). Synthesis of cDNA from 1,000 ng of total RNA and PCR amplification were performed using SYBR PrimeScript RT-PCR kit (Takara Bio, Inc.). The temperature protocol for RT were as follows: $37^{\circ} \mathrm{C}$ for $15 \mathrm{~min}$, $85^{\circ} \mathrm{C}$ for $5 \mathrm{sec}$ and then cooled down to $4^{\circ} \mathrm{C}$. The amplification and detection were performed with an Strategene Mx3005p (Agilent Technologies, Inc.). The thermocycling conditions were as follows: $30 \mathrm{sec}$ denaturation step at $95^{\circ} \mathrm{C}$ followed by 40 cycles of $5 \mathrm{sec}$ denaturation at $95^{\circ} \mathrm{C}, 20 \mathrm{sec}$ annealing at $60^{\circ} \mathrm{C}$ and $20 \mathrm{sec}$ extension at $72^{\circ} \mathrm{C}$. The following primer sequences were synthesized by Shanghai GenePharma Co., Ltd., and used for qPCR: HMGA2 forward, 5'-AAGCAGCAG CAAGAACCAAC-3' and reverse, 5'-AGTCCTCTTCGGCAG ACTCTT-3'; Wnt forward, 5'-TGGAATTGCAACACCCTG GA-3' and reverse, 5'-TTGGCGCTTCCCATCTTCTT-3'; $\beta$-catenin forward, 5'-TATCGTTCTTTTCACTCTGGTGG-3' and reverse, 5'-GCAAGTTCAGACAATACAGCTAAAG-3'; CDK4 forward, 5'-CTGGTGTTTGAGCATGTAGACC-3' and reverse, 5'-GATCCTTGATCGTTTCGGCTG-3'; cyclin D1 forward, 5'-ATGCCAACCTCCTCAACGACC-3' and reverse, 5'-TCAGGGGGATGGTCTCCTTCA-3'; and $\beta$-actin forward, 5'-GATCCACATCTGCTGGAAGG-3' and reverse, 5'-AAG TGTGACGTGGACATCCG-3'. Semi-quantitative RT-qPCRs were repeated 2-4 times with reproducible results. Relative expression levels were calculated using the $2^{-\Delta \Delta \mathrm{Cq}}$ method (37).

Western blotting. HCT 116 cells were harvested and washed two times with ice-cold PBS. Total protein was solubilized using lysis buffer (Applygen Technologies, Inc.) containing $1 \%$ Triton X-100, $150 \mathrm{mM} \mathrm{NaCl}, 2$ mM EDTA (pH, 8.0), $50 \mathrm{mM}$ Tris- $\mathrm{HCl}(\mathrm{pH}, 7.5)$ and $1 \%$ protease inhibitor cocktail (Sigma-Aldrich; Merck KGaA). The lysates were centrifuged at $12,000 \mathrm{x} \mathrm{g}$ for $30 \mathrm{~min}$ at $4^{\circ} \mathrm{C}$. Protein concentration was determined using a standard Coomassie Brilliant Blue Total Protein Assay kit (Nanjing Jiancheng Bioengineering Institute). Protein (90 $\mu \mathrm{g} /$ lane) was subjected to $15 \%$ SDS-PAGE and transferred onto PVDF membranes (MilliporeSigma) after electroblotting at $4^{\circ} \mathrm{C}$. The membranes were blocked with $5 \%$ skim milk for $90 \mathrm{~min}$ at room temperature and incubated with primary antibodies against HMGA2 (GeneTex; cat. no. GTX100519), Wnt (Epitomics; cat. no. 3169-1), $\beta$-catenin (Affinity; cat. no. AF6266), CDK4 (Epitomics; cat. no. 3830-1), Cyclin D1 (Epitomics; cat. no. 1677-1) (all 1:1,000 dilutions) and $\beta$-actin (1:2,000; OriGene Technologies, Inc; cat. no. TA328070) overnight at $4^{\circ} \mathrm{C}$. Following the primary incubation, membranes were incubated with horseradish peroxidase-conjugated sheep anti-mouse IgG or sheep anti-rabbit IgG secondary antibodies (1:5,000; OriGene Technologies, Inc.) $1.5 \mathrm{~h}$ at $37^{\circ} \mathrm{C}$. Protein bands were visualized by chemiluminescence and scanned using an Odyssey® Fc Imaging System (Licor, https://www.selectscience. net/products/odyssey-fc-imaging-system/?prodid=93456).

Statistical analysis. All experiments were performed at least three times and data are presented as the mean \pm SD. Statistical analyses of the datasets were performed using ANOVA, $\chi^{2}$ test, Fisher's exact test and correlation analyses in SPSS 20.0 software (IBM Corp.). One-way ANOVA followed by LSD post-hoc test was used to compare differences between groups. The $\chi^{2}$ test was used to compare the staining results for 
Table I. Clinicopathological parameters of the HMGA2, Wnt, $\beta$-catenin, CDK4 and cyclin D1 proteins in colorectal cancer.

\begin{tabular}{|c|c|c|c|c|c|c|c|c|c|c|c|}
\hline Parameter & $(\mathrm{n}=105)$ & $\begin{array}{l}\text { HMGA2, } \\
\text { n }(\%)\end{array}$ & P-value & $\begin{array}{l}\text { Wnt, } \\
\mathrm{n}(\%)\end{array}$ & P-value & $\begin{array}{l}\beta \text {-catenin, } \\
\mathrm{n}(\%)\end{array}$ & P-value & $\begin{array}{c}\text { CDK4, } \\
\text { n (\%) }\end{array}$ & P-value & $\begin{array}{c}\text { Cyclin D1, } \\
\mathrm{n}(\%)\end{array}$ & P-value \\
\hline \multicolumn{12}{|l|}{ Age, years } \\
\hline$<40$ & 39 & $26(66.7)$ & 0.511 & $30(76.9)$ & 0.419 & $31(79.5)$ & & $29(74.4)$ & & $34(87.2)$ & \\
\hline$\geq 40$ & 66 & $48(72.7)$ & & $55(83.3)$ & & $56(84.8)$ & & $55(83.3)$ & & $53(80.3)$ & \\
\hline \multicolumn{12}{|l|}{$\operatorname{Sex}$} \\
\hline Male & 60 & $43(71.7)$ & 0.757 & $50(83.3)$ & 0.473 & $53(88.3)$ & & $45(75.0)$ & & $49(81.7)$ & \\
\hline Female & 45 & $31(68.9)$ & & $35(77.8)$ & & $34(75.6)$ & & $39(86.7)$ & & $38(84.4)$ & \\
\hline \multicolumn{12}{|c|}{ Tumor size, $\mathrm{cm}$} \\
\hline$<4$ & 29 & $19(65.5)$ & 0.491 & $22(75.9)$ & 0.412 & $21(72.4)$ & 0.119 & $26(89.7)$ & 0.175 & $24(82.8)$ & 0.987 \\
\hline$\geq 4$ & 76 & $55(72.4)$ & & $63(82.9)$ & & $65(85.5)$ & & $58(76.3)$ & & $63(82.9)$ & \\
\hline \multicolumn{12}{|l|}{ Location } \\
\hline Colon & 36 & $24(66.7)$ & 0.536 & $31(86.1)$ & 0.331 & $29(80.6)$ & 0.651 & $32(88.9)$ & 0.126 & $27(75.0)$ & 0.123 \\
\hline Rectum & 69 & $50(72.5)$ & & $54(78.3)$ & & $58(84.1)$ & & $52(75.4)$ & & $60(87.0)$ & \\
\hline \multicolumn{12}{|c|}{ Tumor stage } \\
\hline $\mathrm{I}+\mathrm{II}$ & 27 & $12(44.4)$ & $<0.05$ & $14(51.9)$ & $<0.05$ & $20(74.1)$ & 0.188 & $15(55.6)$ & $<0.05$ & $15(55.6)$ & $<0.05$ \\
\hline III+IV & 78 & $62(79.5)^{\mathrm{a}}$ & & $71(91.0)^{\mathrm{a}}$ & & $67(85.9)$ & & $69(88.5)^{\mathrm{a}}$ & & $72(92.3)^{\mathrm{a}}$ & \\
\hline \multicolumn{12}{|c|}{$\begin{array}{l}\text { Lymph node } \\
\text { metastasis }\end{array}$} \\
\hline Negative & 34 & $14(41.2)$ & $<0.05$ & $26(76.5)$ & 0.418 & $20(58.8)$ & $<0.05$ & $18(52.9)$ & $<0.05$ & $21(61.8)$ & $<0.05$ \\
\hline Positive & 71 & $60(84.5)^{\mathrm{b}}$ & & $59(83.1)$ & & $67(94.4)^{\mathrm{b}}$ & & $66(93.0)^{\mathrm{b}}$ & & $66(93.0)^{\mathrm{b}}$ & \\
\hline \multicolumn{12}{|l|}{$\begin{array}{l}\text { Depth of } \\
\text { invasion }\end{array}$} \\
\hline Shallow & 41 & $32(78.0)$ & 0.173 & $25(61.0)$ & $<0.05$ & $26(63.4)$ & $<0.05$ & $23(56.1)$ & $<0.05$ & 37 (90.2) & 0.121 \\
\hline Deep & 64 & $42(65.6)$ & & $60(93.8)^{\mathrm{c}}$ & & $61(95.3)^{\mathrm{c}}$ & & $61(95.3)^{\mathrm{c}}$ & & $50(78.1)$ & \\
\hline
\end{tabular}

${ }^{\mathrm{a}} \mathrm{P}<0.05$ (I/II vs. III/IV of colorectal carcinoma); ${ }^{\mathrm{b}} \mathrm{P}<0.05$ (without lymph node metastasis vs. with lymph node metastasis in colorectal carcinoma); ${ }^{\mathrm{c}} \mathrm{P}<0.05$ (shallow invasion vs. deep invasion in colorectal carcinoma). HMGA2, high mobility group AT-hook 2; CDK4, cyclin-dependent kinase 4.

target proteins in different groups, and assess the association between protein expression levels and the clinicopathological characteristics of patients with colorectal cancer (Table I). Pearson's (Tables II and III), and Spearman's (Table IV) correlation analyses were performed. Pairwise comparisons was used to compare differences between multiple groups. $\mathrm{P}<0.05$ was considered to indicate a statistically significant difference.

\section{Results}

HMGA2 protein expression in the carcinogenesis of sporadic colorectal tubular adenoma. The fraction of HMGA2-positive cells was significantly higher in SCTA-Ca (74 cases) and SCTA-D (47 cases) samples compared with NCM (0 cases) (Fig. 1A) samples (70.48 vs. $0.00 \%$ and 38.84 vs. $0.00 \%$, respectively; $\mathrm{P}<0.05)$. Notably, significantly more HMGA2-positive cells were observed in SCTA-Ca samples (Fig. 1U) compared with SCTA-D samples (70.48 vs. $38.84 \%$; $\mathrm{P}<0.05)$. Furthermore, HMGA2 expression was markedly lower in adenomas with mild dysplasia (8 cases, $17.4 \%$ ) (Fig. 1F) and moderate dysplasia (17 cases, 38.6\%) (Fig. 1K) compared with severe dysplasia (22 cases, 70.97\%) (Fig. 1P) $(\mathrm{P}<0.05)$, and significant differences were observed between tubular adenomas with mild dysplasia and severe dysplasia, mild dysplasia and moderate dysplasia, and moderate dysplasia and severe dysplasia $(\mathrm{P}<0.05)$.

Clinicopathological significance of HMGA2 in colorectal cancer. Colorectal cancer cases with lymph node metastasis had a significantly higher proportion of HMGA2-positive cells than cases without lymph node metastasis (84.5 vs. $41.2 \%$; $\mathrm{P}<0.05)$. In addition, the percentage of HMGA2-positive cells were closely associated with tumor stage in SCTA-Ca; specifically, it was significantly higher in advanced tumor stages (III/IV) than in early tumor stages (I/II) (79.5 vs. 44.4\%; $\mathrm{P}<0.05)$. Taken together, these results suggest that HMGA2 is significantly associated with lymph node metastasis and colorectal cancer tumor stage (Table I).

Effect of the Wnt/ $\beta$-catenin signaling pathway on the carcinogenesis of sporadic colorectal tubular adenoma. Wnt expression levels in SCTA-D (53/121, 43.8\%) and SCTA-Ca $(85 / 105,81.0 \%$; Fig. 1V) cases were significantly higher compared with the results for NCM (2/37, 5.40\%; $\mathrm{P}<0.05$; Fig. 1B). Furthermore, Wnt expression levels were significantly lower in cases of adenoma with mild dysplasia (15/46, 32.6\%; Fig. 1G) and moderate dysplasia (17/44, 38.6\%; Fig. 1L) compared with severe dysplasia (21/31, 67.7\%; 
Table II. Correlation between the expression levels of HMGA2 and Wnt, $\beta$-catenin, CDK4 and cyclin D1 in sporadic colorectal tubular adenomas with different dysplasia based on immunohistochemistry analysis.

\begin{tabular}{|c|c|c|c|c|c|c|c|c|}
\hline \multirow[b]{2}{*}{ HMGA2 } & \multicolumn{2}{|c|}{ Wnt } & \multicolumn{2}{|c|}{$\beta$-catenin } & \multicolumn{2}{|c|}{ CDK4 } & \multicolumn{2}{|c|}{ Cyclin D1 } \\
\hline & + & - & + & - & + & - & + & - \\
\hline+ & 25 & 23 & 45 & 10 & 29 & 20 & 31 & 16 \\
\hline- & 17 & 56 & 16 & 50 & 14 & 58 & 20 & 54 \\
\hline$r$ & 0.296 & & 0.573 & & 0.408 & & 0.384 & \\
\hline P-value & $<0.05^{\mathrm{a}}$ & & $<0.05^{\mathrm{a}}$ & & $<0.05^{\mathrm{a}}$ & & $<0.05^{\mathrm{a}}$ & \\
\hline
\end{tabular}

${ }^{\text {aP }}<0.05$. HMGA2, high mobility group AT-hook 2; CDK4, cyclin-dependent kinase 4.

Table III. Correlation between the expression levels of HMGA2 and Wnt, $\beta$-catenin, CDK4 and cyclin D1 in sporadic colorectal tubular adenomas with cancerous changes.

\begin{tabular}{|c|c|c|c|c|c|c|c|c|}
\hline \multirow[b]{2}{*}{ HMGA2 } & \multicolumn{2}{|c|}{ Wnt } & \multicolumn{2}{|c|}{$\beta$-catenin } & \multicolumn{2}{|c|}{ CDK4 } & \multicolumn{2}{|c|}{ Cyclin D1 } \\
\hline & + & - & + & - & + & - & + & - \\
\hline+ & 70 & 10 & 69 & 6 & 68 & 9 & 64 & 11 \\
\hline- & 14 & 11 & 10 & 20 & 9 & 19 & 12 & 18 \\
\hline$r$ & 0.335 & & 0.614 & & 0.562 & & 0.458 & \\
\hline P-value & $<0.05^{\mathrm{a}}$ & & $<0.05^{\mathrm{a}}$ & & $<0.05^{\mathrm{a}}$ & & $<0.05^{\mathrm{a}}$ & \\
\hline
\end{tabular}

${ }^{\mathrm{a}}<0.05$. HMGA2, high mobility group AT-hook 2; CDK4, cyclin-dependent kinase 4.

Table IV. Correlation between the expression levels of HMGA2 and Wnt, $\beta$-catenin, CDK4 and cyclin D1 according to the immunohistochemical score.

\begin{tabular}{lccccccc}
\hline Variable & $\mathrm{n}$ & $\mathrm{I}$ & $\mathrm{II}$ & $\mathrm{III}$ & $\mathrm{Ca}$ & CC & P-value \\
\hline HMGA2 & 0 & $0.35 \pm 0.77$ & $2.23 \pm 1.49$ & $4.68 \pm 1.43$ & $6.11 \pm 1.38$ & \\
Wnt & $0.05 \pm 0.23$ & $0.33 \pm 0.47$ & $1.86 \pm 1.13$ & $3.55 \pm 1.15$ & $5.61 \pm 1.33$ & $0.933^{\mathrm{a}, \mathrm{b}}$ & $<0.01$ \\
$\beta$-catenin & 0 & $2.17 \pm 0.77$ & $4.16 \pm 0.89$ & $6.13 \pm 1.15$ & $8.81 \pm 1.63$ & $0.870^{\mathrm{a}, \mathrm{c}}$ & $<0.01$ \\
CDK4 & $0.08 \pm 0.28$ & $0.76 \pm 1.06$ & $3.10 \pm 1.46$ & $7.50 \pm 1.50$ & $10.4 \pm 1.21$ & $0.957^{\mathrm{a}, \mathrm{d}}$ & $<0.01$ \\
Cyclin D1 & $3.19 \pm 0.40$ & $3.39 \pm 0.80$ & $5.41 \pm 1.72$ & $8.42 \pm 1.40$ & $10.4 \pm 1.58$ & $0.915^{\mathrm{a}, \mathrm{e}}$ & $<0.01$ \\
\hline
\end{tabular}

n, normal colorectal mucosa; I, colorectal tubular adenoma with mild dysplasia; II, colorectal tubular adenoma with moderate dysplasia; III, colorectal tubular adenoma with severe dysplasia; $\mathrm{Ca}$, colorectal carcinoma; $\mathrm{CC}$, correlation coefficient. ${ }^{\mathrm{a}} \mathrm{Correlation}$ is significant at the 0.01 level (two-tailed). ${ }^{\mathrm{b}} \mathrm{HMGA} 2 \mathrm{vs.} \mathrm{Wnt;}{ }^{\mathrm{c} H M G A} 2$ vs. $\beta$-catenin; ${ }^{\mathrm{d}} \mathrm{HMGA} 2$ vs. CDK4; ${ }^{\mathrm{e}} \mathrm{HMGA} 2$ vs. cyclin D1. HMGA2, high mobility group AT-hook 2; CDK4, cyclin-dependent kinase 4.

P<0.05; Fig. 1Q), with significant differences observed between tubular adenomas with mild dysplasia and severe dysplasia, and between moderate dysplasia and severe dysplasia $(\mathrm{P}<0.05)$.

$\beta$-catenin, a key factor in the Wnt signaling pathway, can initiate the activation of the Wnt pathway via nuclear translocation $(38,39)$. The incidence of positive nuclear expression of $\beta$-catenin was (0/37) $0.00 \%,(61 / 121) 50.4 \%$ and $(87 / 105) 82.9 \%$ in NCM (Fig. 1C), SCTA-D and SCTA-Ca (Fig. 1W) cases, respectively $(\mathrm{P}<0.05)$. $\beta$-catenin-positive cells accounted for (10/46) $21.7 \%$, (23/44) $52.3 \%$ and (28/31) $90.3 \%$ of cells in mild (Fig. $1 \mathrm{H})$, moderate (Fig. 1M) and severe dysplasia adenomas
(Fig. 1R), respectively, with significant differences observed between tubular adenomas with mild dysplasia and severe dysplasia, mild dysplasia and moderate dysplasia, and moderate dysplasia and severe dysplasia in the nucleus $(\mathrm{P}<0.05)$.

In NCM (CDK4, Fig. 1D; cyclin D1, Fig. 1E), SCTA-D and SCTA-Ca (CDK4, Fig. 1X; cyclin D1, Fig. 1Y) cases, the incidence of positive CDK4 and cyclin D1 expression levels were $(3 / 37) 8.10 \%,(51 / 121) 42.1 \%$ and $(84 / 105) 80.0 \%$; and (7/37) $18.9 \%,(60 / 121) 49.6 \%$ and $(87 / 105) 82.9 \%$, respectively. Statistically significant differences were observed in pairwise comparisons between NCM, SCTA-D and SCTA-Ca cases 

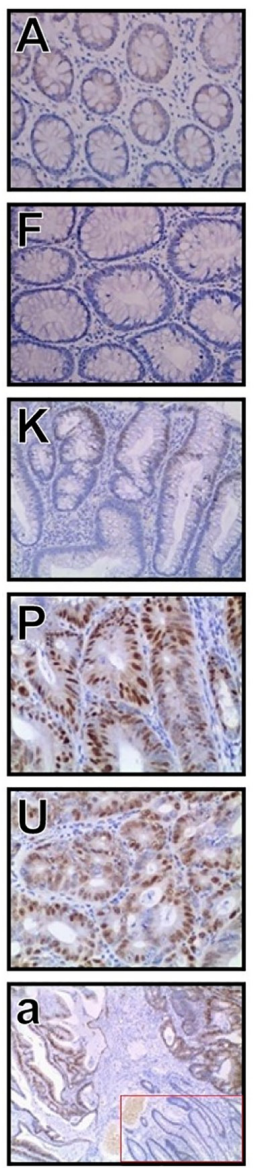
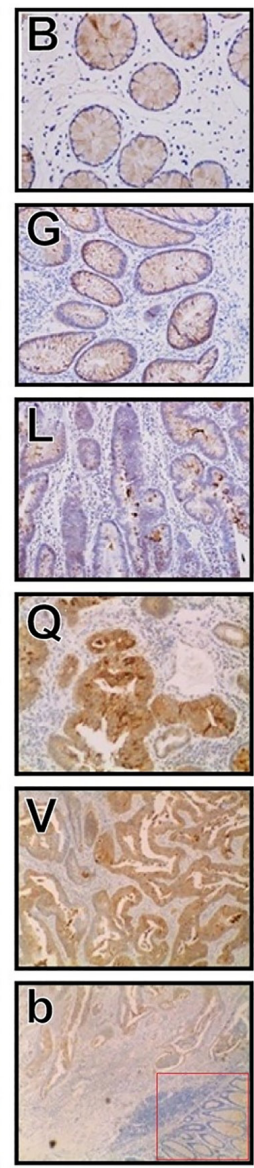
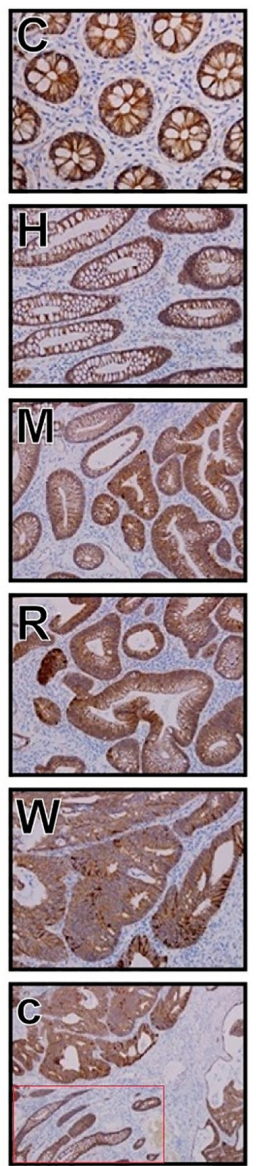
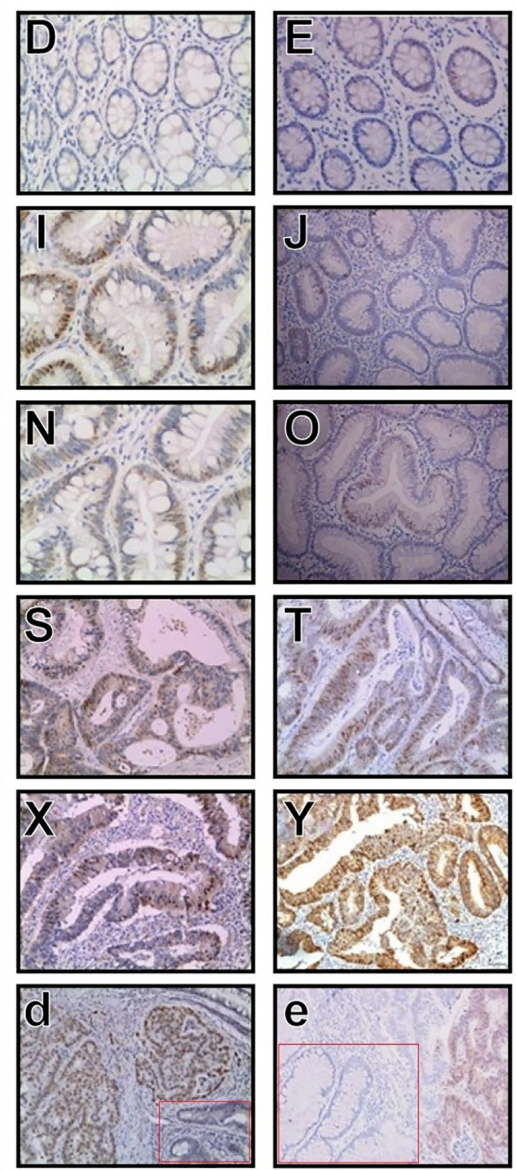

Figure 1. Expression levels of HMGA2, Wnt, $\beta$-catenin, CDK4 and cyclin D1 in NCM, SCTA-D and SCTA-Ca cases. From left to right, (A-E) NCM, (F-J) colorectal tubular adenomas with mild dysplasia, (K-O) colorectal tubular adenomas with moderate dysplasia, (P-T) colorectal tubular adenomas with severe dysplasia, (U-Y) SCTA-Ca and (a-e) SCTA-D vs. SCTA-Ca (SCTA-D is presented in the red frames). From top to bottom, tissues were stained for (A, F, K, P, U and a) HMGA2, (B, G, L, Q, V and b) Wnt, (C, H, M, R, W and c) $\beta$-catenin, (D, I, N, S, X and d) CDK4 and (E, J, O, T, Y and e) cyclin D1. (A-Y) magnification, x200; (a-e) magnification, x100. HMGA2, high mobility group AT-hook 2; CDK4, cyclin-dependent kinase 4; NCM, normal colorectal mucosa; SCTA-D, sporadic colorectal tubular adenomas with dysplasia; SCTA-Ca, sporadic colorectal tubular adenomas with cancerous changes.

$(\mathrm{P}<0.05)$. For CDK4 and cyclin D1, the positive expression rates were $(7 / 46) 15.2 \%,(16 / 44) 36.4 \%$ and $(28 / 31) 90.3 \%$; and $(9 / 46)$ $19.6 \%,(23 / 44) 52.3 \%$ and (28/31) 90.3\% in mild (CDK4, Fig. 1I; cyclin D1, Fig. 1J), moderate (CDK4, Fig. 1N; cyclin D1, Fig. 1O) and severe dysplasia adenomas (CDK4, Fig. 1S; cyclin D1, Fig. 1T), respectively. Significant differences were observed between tubular adenomas with mild dysplasia and severe dysplasia $(\mathrm{P}<0.05)$ (Fig. 1D, I, N, S, X, d, E, J, O, T, Y and e).

Differential clinicopathological significance of Wnt, $\beta$-catenin, CDK4 and cyclin D1 in colorectal cancer. SCTA-Ca cases with lymph node metastasis had a significantly higher proportion of $\beta$-catenin-positive cells than cases without lymph node metastasis (94.4 vs. 58.8\%; $\mathrm{P}<0.05)$. Similar results were obtained for CDK4 and cyclin D1 positive expression with respect to lymph node metastasis $(93.0 \%$ in the metastatic group vs. $52.9 \%$ in the non-metastatic group for CDK4, and $93.0 \%$ in the metastatic group vs. $61.8 \%$ in the non-metastatic group for cyclin $\mathrm{D} 1 ; \mathrm{P}<0.05)$. The percentages of Wnt-, CDK4- and cyclin D1-positive cells were closely associated with tumor stage in SCTA-Ca. The percentages of positive cells were significantly higher in cases of advanced tumor stages (III/IV) than in cases of early tumor stages (I/II) (91.0 vs. $51.9 \%$ for Wnt; 88.5 vs. $55.6 \%$ for CDK4, and 92.3 vs. $55.6 \%$ for cyclin $\mathrm{D} 1 ; \mathrm{P}<0.05)$. Furthermore, the percentages of Wnt-, $\beta$-catenin- and CDK4-positive cells were closely associated with invasion depth in SCTA-Ca cases. The percentages of positive cells were significantly higher in cases of deep invasion depth than in cases of shallow invasion depth (93.8 vs. $61.0 \%$ for Wnt; 95.3 vs. $63.4 \%$ for $\beta$-catenin, and 95.3 vs. $56.1 \%$ for $\mathrm{CDK} 4$; $\mathrm{P}<0.05$ ) (Table I).

Correlation between the expression levels of HMGA2, Wnt, $\beta$-catenin, CDK4 and cyclin D1 in colorectal cancer. Correlation between the expression levels of HMGA2 and Wnt, $\beta$-catenin, CDK4 and cyclin D1 were assessed in the present study. As presented in Table II, in SCTA-D cases, HMGA2 expression increased as the expression levels of Wnt, $\beta$-catenin, CDK4 and cyclin D1 increased ( $r$ values, 0.296 for Wnt; 0.573 for $\beta$-catenin, 0.408 for CDK4 and 0.384 for cyclin $\mathrm{D} 1 ; \mathrm{P}<0.05$ ).

As presented in Table III, in SCTA-Ca cases, HMGA2 expression increased as the expression levels of Wnt, $\beta$-catenin, CDK4 and cyclin D1 increased ( $r$ values, 0.335 for Wnt; 0.614 for $\beta$-catenin; 0.562 for CDK4 and 0.458 for cyclin $\mathrm{D} 1 ; \mathrm{P}<0.05$ ).

As presented in Table IV, the expression levels of HMGA2 were positively correlation with the expression levels of Wnt, $\beta$-catenin, CDK4 and cyclin D1, respectively, in both SCTA-Ca and SCTA-D cases according to the immunohistochemical 

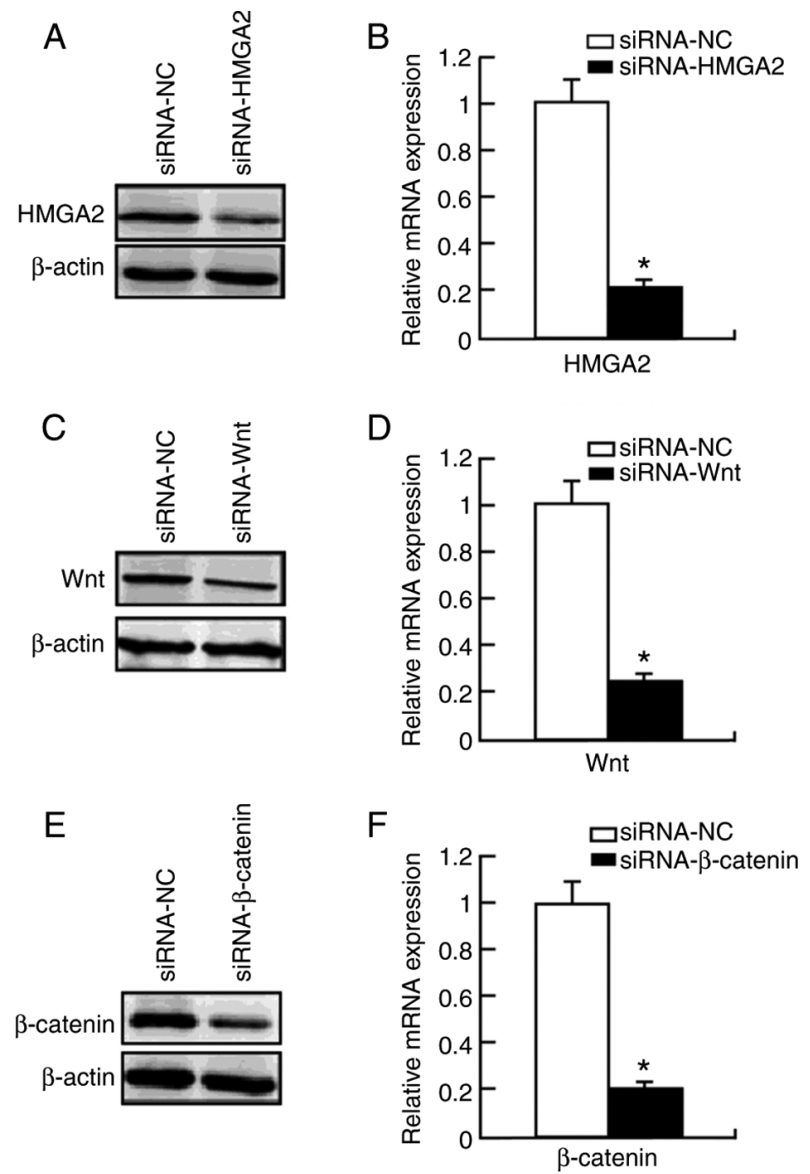

Figure 2. Protein and mRNA expression levels of HMGA2, Wnt and $\beta$-catenin following transfection with siRNA in HCT 116 cells. (A) HMGA2 protein expression significantly decreased following transfection with siRNA-HMGA2. (B) HMGA2 mRNA expression significantly decreased following transfection with siRNA-HMGA2. (C) Wnt protein expression significantly decreased following transfection with siRNA-Wnt. (D) Wnt mRNA expression significantly decreased following transfection with siRNA-Wnt. (E) $\beta$-catenin protein expression significantly decreased following transfection with siRNA- $\beta$-catenin. (F) $\beta$-catenin mRNA expression significantly decreased following transfection with siRNA- $\beta$-catenin. ${ }^{*} \mathrm{P}<0.05$ vs. siRNA-NC group. HMGA2, high mobility group AT-hook 2; si, small interfering; NC, negative control.

score $(\mathrm{P}<0.05)$. Taken together, these results suggest that there is a positive correlation between the expression levels of HMGA2 and Wnt, $\beta$-catenin, CDK4 and cyclin D1 in both SCTA-Ca and SCTA-D cases.

HMGA2 inhibits activation of the Wnt/ $\beta$-catenin signaling pathway in HCT 116 cells. To further investigate the contribution of HMGA2 to the Wnt/ $\beta$-catenin signaling pathway, the present study used specific siRNA to knockdown HMGA2 expression in HCT 116 cells. Compared with the control group (mRNA, 1.05 \pm 0.13 ; protein, $1.11 \pm 0.15$ ), transfection with siRNA-HMGA2 significantly decreased HMGA2 protein $(0.32 \pm 0.04 ; \mathrm{P}<0.05)$ and mRNA $(0.29 \pm 0.03 ; \mathrm{P}<0.05)$ expression levels (Fig. 2A and B). Notably, transfection with siRNA-HMGA2 significantly decreased $\beta$-catenin protein $(0.59 \pm 0.03$, to $\sim 45 \%$ after $48 \mathrm{~h})$ and $\mathrm{mRNA}(0.61 \pm 0.01$, to $\sim 40 \%$; $\mathrm{P}<0.05)$ expression levels compared with the control group (mRNA, 0.99 \pm 0.01 ; protein, 0.97 \pm 0.15 ) (Fig. 3). Furthermore, transfection with siRNA-HMGA2 significantly decreased

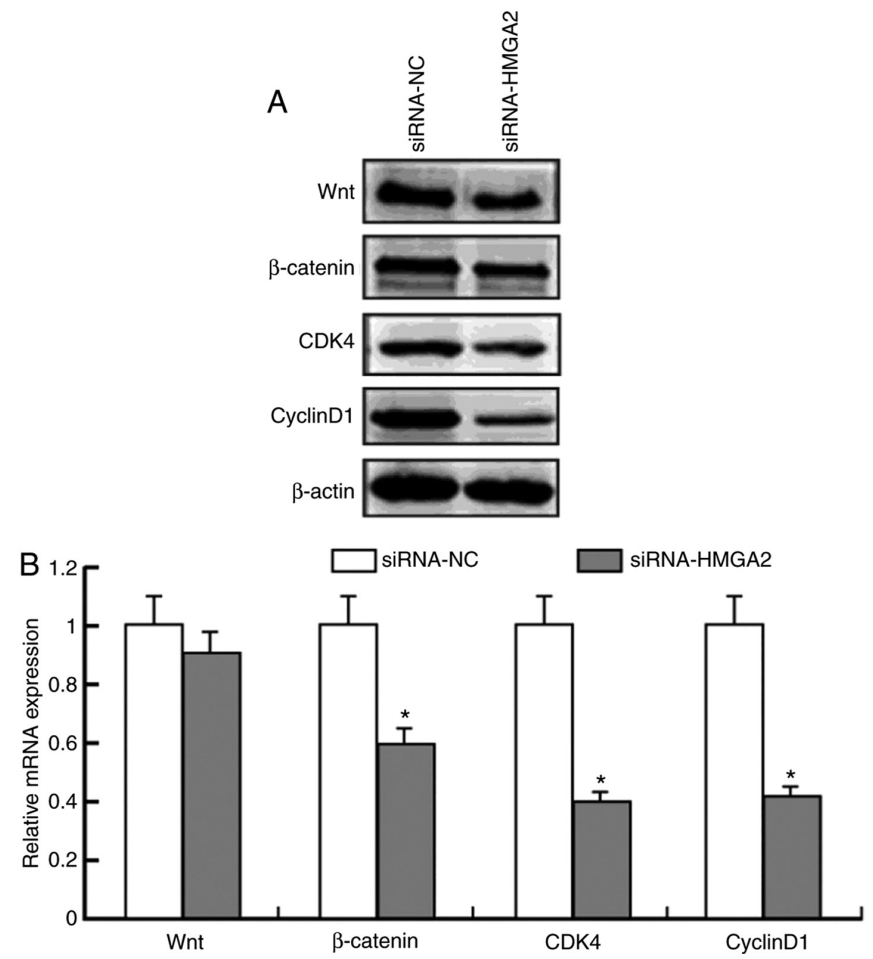

Figure 3. Protein and mRNA expression levels of Wnt, $\beta$-catenin, CDK4 and Cyclin D1 following transfection with siRNA-HMGA2. (A) Protein expression levels of Wnt, $\beta$-catenin, CDK4 and Cyclin D1 following transfection with siRNA-HMGA2, with $\beta$-actin as the loading control. (B) mRNA expression levels of Wnt, $\beta$-catenin, CDK4 and Cyclin D1 following transfection with siRNA-HMGA2. ${ }^{*} \mathrm{P}<0.05$ vs. siRNA-NC group. si, small interfering; NC, negative control; HMGA2, high mobility group AT-hook 2; CDK4, cyclin-dependent kinase.

the expression levels of the $\beta$-catenin downstream target genes (40), CDK4 $(0.40 \pm 0.03$, to $\sim 55 \%$ for protein; $0.41 \pm 0.02$, to $\sim 60 \%$ for mRNA; $\mathrm{P}<0.05)$ and cyclin $\mathrm{D} 1(0.41 \pm 0.02$, to $\sim 53 \%$ for protein; $0.43 \pm 0.01$, to $\sim 58 \%$ for mRNA; $\mathrm{P}<0.05$ ) (Fig. 3). Notably, HMGA2 knockdown had no effect on Wnt expression $(0.90 \pm 0.01$, to $\sim 9.1 \%$ for protein; $0.92 \pm 0.01$, to $\sim 9 \%$ for mRNA; P>0.05) (Fig. 3). Collectively, these results suggest that HMGA2 protein regulates $\mathrm{Wnt} / \beta$-catenin signaling in colon cancer cells.

Wnt- or $\beta$-catenin-specific siRNA inhibit HMGA2 expression in HCT 116 cells. To determine whether knockdown of the Wnt/ $\beta$-catenin signaling pathway inhibits HMGA2, HCT 116 cells were transfected with siRNA-Wnt or siRNA- $\beta$-catenin, and HMGA2 protein expression levels were detected via RT-qPCR and western blot analyses. Transfection with siRNA-Wnt significantly decreased Wnt protein $(0.27 \pm 0.02 ; \mathrm{P}<0.05)$ and mRNA $(0.25 \pm 0.04 ; \mathrm{P}<0.05)$ expression levels compared with the control group (mRNA, 1.01 \pm 0.11 ; protein, $1.10 \pm 0.12$ ) (Fig. $2 \mathrm{C}$ and D). In addition, transfection with siRNA- $\beta$-catenin significantly decreased $\beta$-catenin protein $(0.22 \pm 0.03 ; \mathrm{P}<0.05)$ and mRNA $(0.19 \pm 0.01$; $\mathrm{P}<0.05)$ expression levels compared with the control group (mRNA, 1.03 \pm 0.43 ; protein, 1.09 \pm 0.11 ) (Fig. 2E and F).

As presented in Fig. 4, transfection with siRNA-Wnt significantly decreased HMGA2 protein $(0.49 \pm 0.02 ; \mathrm{P}<0.05)$ and mRNA $(0.50 \pm 0.03 ; \mathrm{P}<0.05)$ expression levels compared with the control group (mRNA, 1.05 \pm 0.13 ; protein, $1.09 \pm 0.18$ ). Similarly, 

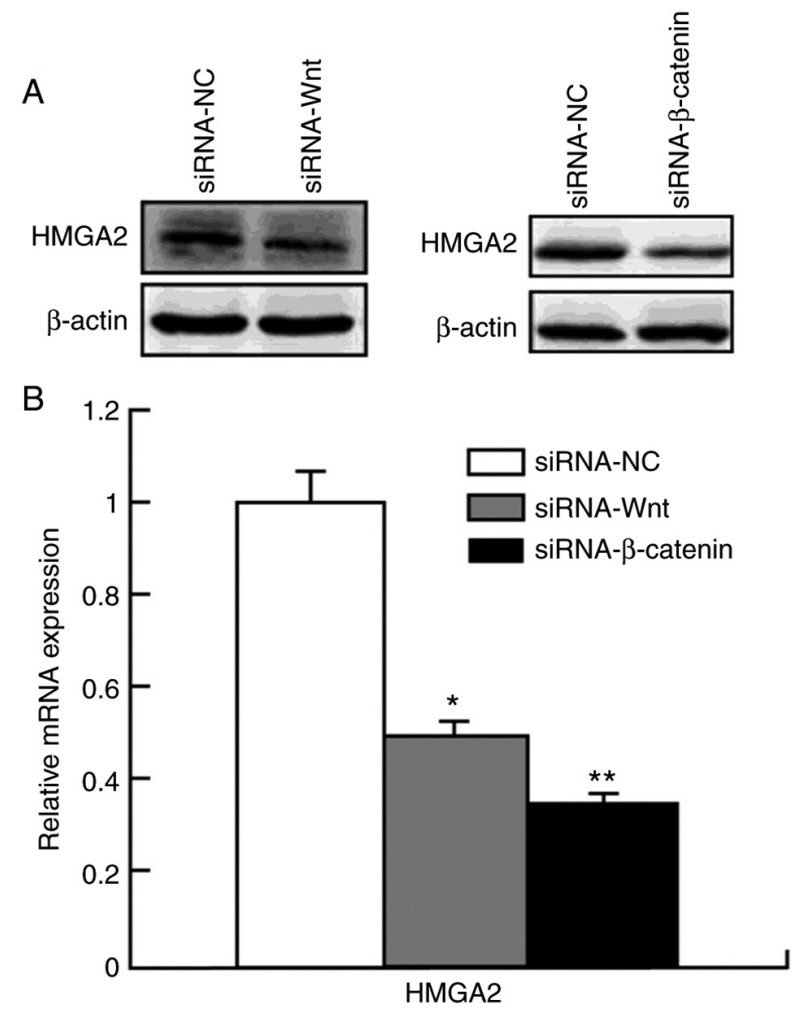

Figure 4. Protein and mRNA expression levels of HMGA2 following transfection with siRNA-Wnt and siRNA- $\beta$-catenin. HMGA2 expression was significantly inhibited following transfection with siRNA-Wnt and siRNA- $\beta$-catenin at the (A) protein and (B) mRNA (B) levels in HCT 116 cells. ${ }^{*} \mathrm{P}<0.05$ vs. siRNA-NC group; ${ }^{* * *} \mathrm{P}<0.01$ vs. siRNA-NC group. HMGA2, high mobility group AT-hook 2; si, small interfering; NC, negative.

transfection with siRNA- $\beta$-catenin significantly decreased HMGA2 protein $(0.35 \pm 0.02 ; \mathrm{P}<0.05)$ and mRNA $(0.38 \pm 0.01$; $\mathrm{P}<0.01)$ expression levels compared with the control group (mRNA, 1.10 \pm 0.11 ; protein, $0.99 \pm 0.04$ ). Taken together, these results suggest that suppressing Wnt or $\beta$-catenin expression levels decreases HMGA2 protein expression. Thus HMGA2 expression is strongly regulated by the Wnt//-catenin signaling pathway.

Combining the experimental results of histology and cytology, both the Wnt/ $\beta$-catenin signaling pathway and HMGA2 play important roles in the carcinogenesis of sporadic colorectal tubular adenoma. In addition, the Wnt/ $\beta$-catenin signaling pathway and HMGA2 were suggested to form a two-way feedback loop. The proposed model for Wnt/ $/$-catenin signaling pathway and HMGA2 interactions is presented in Fig. 5. This model shows that transfection with siRNA-Wnt and siRNA- $\beta$-catenin decreased HMGA2 expression. Furthermore, transfection with siRNA-HMGA2 decreased the expression levels of $\beta$-catenin, CDK4 and Cyclin D1. However, further studies are required to determine the role of the $\mathrm{Wnt} / \beta$-catenin/HMGA2 axis in carcinomatous conversion. Thus, regulation of the Wnt/ $\beta$-catenin/HMGA 2 signaling axis in the carcinogenesis of sporadic colorectal tubular adenoma may open new opportunities for future therapies.

\section{Discussion}

The Wnt/ $/$-catenin signaling pathway mediates the carcinogenesis of sporadic colorectal tubular adenoma, and the strength

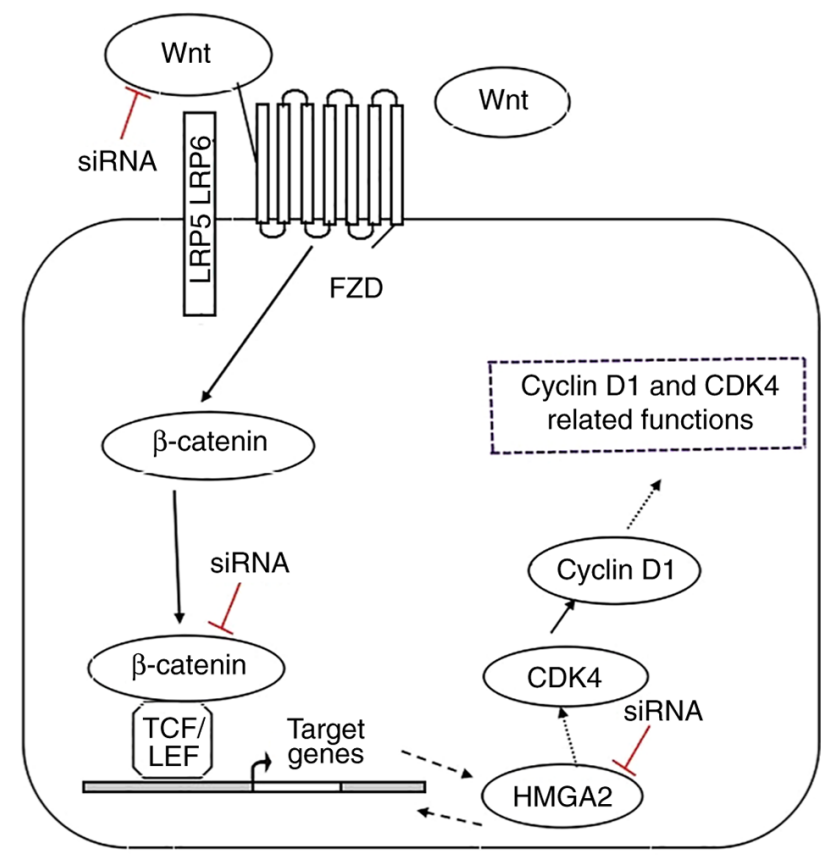

Figure 5. Proposed model for Wnt/ $\beta$-catenin signaling and HMGA2 interactions. Wnt activates canonical $\beta$-catenin signaling, which upregulates HMGA2 expression and self-renewal by induction of cell cycle proliferation. Transfection with siRNA-Wnt and siRNA- $\beta$-catenin decrease HMGA2 expression. HMGA2 regulates several genes that are closely associated with the Wnt/ $\beta$-catenin pathway by directly binding to their promoters, thereby activating the Wnt/ $\beta$-catenin pathway. Transfection with siRNA-HMGA2 decreases the expression levels of $\beta$-catenin, CDK4 and cyclin D1. Black dashed arrows and red blocking bars represent a possible mechanism of HMGA2 action and/or loss of $\beta$-catenin transcriptional activity. HMGA2, high mobility group AT-hook 2; si, small interfering; CDK4, cyclin-dependent kinase; TCF/LEF, T-cell factor/lymphoid enhancing factor; FZD, Frizzled.

and duration of $\mathrm{Wnt} / \beta$-catenin signaling are dependent on the translocation of $\beta$-catenin from the membrane/cytoplasm to the nucleus and on the formation of the $\beta$-catenin-TCF/LEF complex (41). Previous studies have reported that HMGA2 and the Wnt/ $\beta$-catenin member, TCF/LEF, contain a similar domain, the HMG-containing DNA binding domain, which enhances the transcriptional activity of $\beta$-catenin and TCF/LEF binding $(30,42)$. However, whether there is a direct association between HMGA2 and $\mathrm{Wnt} / \beta$-catenin in the carcinogenesis of sporadic colorectal tubular adenoma remains unknown. The results of the present study demonstrated that HMGA2 expression gradually increased from the normal mucosa and tubular adenomas, with different degrees of dysplasia, to converted carcinomatous tissues. This supports the role of HMGA2 as a tumor activator in the carcinogenesis of SCTA. In addition, the results demonstrated that HMGA2 and the Wnt/ $\beta$-catenin signaling pathway can form a bi-directional regulation feedback loop in colorectal cancer cells. These results help us better understand carcinomatous conversion.

The role of HMGA2 in tumorigenesis has been extensively studied in recent years. It has been reported that HMGA2 expression is upregulated in different types of human cancer, such as esophageal squamous cell carcinoma (43), gastric cancer (39) and bladder cancer (44). A previous study demonstrated that the nuclear expression of HMGA2 increases in advanced stages of colorectal cancer (23). In the present study, IHC analysis was performed to detect HMGA2 expression in normal colorectal mucosa, tubular adenomas with different degrees of dysplasia 
and tubular adenomas with carcinomatous changes. The gradual increase in HMGA2 expression suggests it is involved in the progression to carcinomatous adenomas. Notably, a greater number of SCTA-D cases were assessed $(n=121)$, and the results revealed an association between HMGA2 protein expression and SCTA-D. In SCTA-Ca cases, HMGA2 expression was significantly associated with tumor stage and lymph node metastasis. In addition, the results demonstrated a positive correlation between HMGA2 and the Wnt/ $\beta$-catenin signaling pathway. Taken together, these results suggest that HMGA2 functions as a tumor activator by strengthening Wnt signaling in the carcinogenesis of sporadic colorectal tubular adenoma. Both HMGA 2 and $\mathrm{Wnt} / \beta$-catenin play important roles in the formation of colorectal adenomas and in carcinomatous conversion, and there is a synergy between the two in these processes.

The control mechanism of HMGA2 and the Wnt pathway is not uniform, Yang et al (45) demonstrated that HMGA2 activates the Wnt/ $\beta$-catenin pathway in acute myeloid leukemia; However, the Wnt pathway exhibits epistatic interactions with HMGA2 in transgenic murine breast cancer (20). In the present study, HMGA 2 and the Wnt pathway clearly played a role in the carcinogenesis of adenomas. To further clarify the association between HMGA2 and the Wnt pathway, a colorectal cancer cell line was used to examine the effects of siRNA on HMGA2, Wnt and $\beta$-catenin expression. Mechanistically, the results demonstrated that Wnt activates canonical $\beta$-catenin signaling, leading to the regulation of HMGA2, and HMGA2 may regulate proliferation by modulating the expression levels of CDK4 and cyclin D1 in colorectal cancer. Accordingly, HMGA2 is essential and necessary for proliferation in colorectal cancer (28). Furthermore, using siRNA-HMGA2 transfected colorectal cancer cells, the results demonstrated that HMGA2 also regulated $\beta$-catenin. Taken together, these results suggest that there is an interaction between HMGA2 and the Wnt/ $\beta$-catenin signaling pathway in colorectal cancer, indicating that Wnt/ $\beta$-catenin and HMGA 2 form a two-way feedback loop. Thus, it can be speculated that HMGA2 interacts with the Wnt/ $\beta$-catenin signaling pathway in sporadic colorectal tubular adenoma carcinogenesis.

Given that the critical role of Wnt/ $\beta$-catenin signaling in the etiology of colorectal cancer (CRC) has been established, several studies have been performed to identify key molecular players that can represent concrete targets for CRC chemoprevention and therapy (46). The Wnt/ $\beta$-catenin pathway, also known as the canonical Wnt pathway, controls the self-renewal of intestinal stem cells and is crucial for preserving intestinal homeostasis, Sustained Wnt/ $\beta$-catenin signaling activation triggers hyperproliferation and oncogenic transformation of intestinal epithelial cells, resulting in the onset of CRC (47). Increasing evidence suggest that HMGA2 participates in several processes of cancer development and progression, such as proliferation, differentiation, transformation, metastasis and angiogenesis (48). Most studies have focused on the oncogenic role of HMGA2 $(28,49)$. The results of the present study demonstrated that HMGA2 regulated the Wnt/ $\beta$-catenin signaling pathway in $\mathrm{HCT}$ 116 cells. Thus, it was hypothesized that HMGA2 may also play an indirect role in cell proliferation and other functional changes via the Wnt signaling pathway. This is also a limitation of the present study. Thus, prospective studies will assess proliferation and metastasis.
In conclusion, the results of the present study confirmed that both HMGA2 and Wnt/ $\beta$-catenin play important roles in the formation of colorectal adenomas and in carcinomatous conversion, and have a synergistic effect. In addition, Wnt/ $\beta$-catenin/HMGA2 form a two-way feedback loop. With regards to the Wnt/ $\beta$-catenin/HMGA2 signaling axis, the results of the present study enrich our understanding of the carcinogenesis of sporadic colorectal tubular adenoma.

\section{Acknowledgements}

Not applicable.

\section{Funding}

No funding was received.

\section{Availability of data and materials}

The datasets used and/or analyzed during the current study are available from the corresponding author on reasonable request.

\section{Authors' contributions}

DL and WW were responsible for the conception and design of the present study, and critically revised the manuscript for important intellectual content. DL, JW, YC and WW were responsible for the data acquisition, selection and analysis, and clinical interpretation of the data. DL, HY, WL and JC performed the experiments and analyzed the data. DL and JW confirmed the authenticity of all the raw data. All authors contributed to writing the manuscript. All authors have read and approved the final manuscript.

\section{Ethics approval and consent to participate}

The present study was approved by the Ethics Committee of The Second Hospital of Hebei Medical University (approval no. 2014057; Shijiazhuang, China) and written informed consent was provided by all participants prior to the study start.

\section{Patient consent for publication}

Not applicable.

\section{Competing interests}

The authors declare that they have no competing interests.

\section{References}

1. Dilly CK and Kahi CJ: Does increased adenoma detection reduce the risk of colorectal cancer, and how good do we need to be? Curr Gastroenterol Rep 21: 9, 2019.

2. Fabišíková K, Behulová RL and Repiska V: Molecular biomarkers in the diagnostic of patients with colorectal cancer. Neuro Endocrinol Lett 40: 215-221, 2019.

3. Roberts BS, Hardigan AA, Moore DE, Ramaker RC, Jones AL, Fitz-Gerald MB, Cooper GM, Wilcox CM, Kimberly RP and Myers RM: Discovery and validation of circulating biomarkers of colorectal adenoma by high-depth small RNA sequencing. Clin Cancer Res 24: 2092-2099, 2018. 
4. Versace VL, Forsyth AD, Vaughan R, Morrice MG and Morphett BJ: Evidence of elevated colorectal cancer and adenoma rates for regional National bowel cancer screening program participants. Aust J Rural Health 26: 63-64, 2018.

5. Zhou H, Shen Z, Zhao J, Zhou Z and Xu Y: Distribution characteristics and risk factors of colorectal adenomas. Zhonghua Wei Chang Wai Ke Za Zhi 21: 678-684, 2018 (In Chinese)

6. Yang B, Mao L, Li Y, Li Q, Li X, Zhang Y and Zhai Z: $\beta$-catenin, leucine-rich repeat-containing $\mathrm{G}$ protein-coupled receptor 5 and GATA-binding factor 6 are associated with the normal mucosa-adenoma-adenocarcinoma sequence of colorectal tumorigenesis. Oncol Lett 15: 2287-2295, 2018.

7. Lee JK, Jensen CD, Levin TR, Doubeni CA,Zauber AG, Chubak J, Kamineni AS, Schottinger JE, Ghai NR, Udaltsova N, et al: Long-term risk of colorectal cancer and related death after adenoma removal in a large, community-based population. Gastroenterology 158: 884-894.e5, 2020

8. Lochhead P, Chan AT, Giovannucci E, Fuchs CS, Wu K, Nishihara R, O'Brien M and Ogino S: Progress and opportunities in molecular pathological epidemiology of colorectal premalignant lesions. Am J Gastroenterol 109: 1205-1214, 2014.

9. Dinarvand P, Davaro EP, Doan JV, Ising ME, Evans NR, Phillips NJ, Lai J and Guzman MA: Familial adenomatous polyposis syndrome: An update and review of extraintestinal manifestations. Arch Pathol Lab Med 143: 1382-1398, 2019.

10. Taherian M, Lotfollahzadeh S, Daneshpajouhnejad P and Arora K: Tubular Adenoma. In: StatPearls. StatPearls Publishing LLC, Treasure Island, FL, 2020

11. Tischoff I and Tannapfel A: Precancerous colorectal tumors Internist (Berl) 54: 691-698, 2013 (In German).

12. Nguyen LH, Goel A and Chung DC: Pathways of colorectal carcinogenesis. Gastroenterology 158: 291-302, 2020.

13. Guo Y, Bao Y and Yang W: Regulatory miRNAs in colorectal carcinogenesis and metastasis. Int J Mol Sci 18: 890, 2017.

14. Schatoff EM, Leach BI and Dow LE: Wnt signaling and colorectal cancer. Curr Colorectal Cancer Rep 13: 101-110, 2017

15. Wang L, Li D, Liu Y, Wang Y, Cui J, Cui A and Wu W: Expression of RUNX3 and $\beta$-catenin in the carcinogenesis of sporadic colorectal tubular adenoma. Tumour Biol 35: 6039-6046, 2014.

16. Kirchner T and Brabletz T: Patterning and nuclear beta-catenin expression in the colonic adenoma-carcinoma sequence. Analogies with embryonic gastrulation. Am J Pathol 157: 1113-1121, 2000.

17. Kirsanov K, Fetisov T, Lesovaya EA, Maksimova V, Trukhanova L, Antoshina E, Gor'kova T, Morozova O, Safina A, Fleyshman D, et al: Prevention of colorectal carcinogenesis by DNA-binding small-molecule curaxin CBL0137 involves suppression of Wnt signaling. Cancer Prev Res (Phila) 13: 53-64, 2020.

18. Lo YH, Noah TK, Chen MS, Zou W, Borras E, Vilar E and Shroyer NF: SPDEF induces quiescence of colorectal cancer cells by changing the transcriptional targets of $\beta$-catenin. Gastroenterology 153: 205-218.e8, 2017.

19. Dong J, Wang R, Ren G, Li X, Wang J, Sun Y, Liang J, Nie Y, Wu K, Feng B, et al: HMGA2-FOXL2 axis regulates metastases and epithelial-to-mesenchymal transition of chemoresistant gastric cancer. Clin Cancer Res 23: 3461-3473, 2017.

20. El Ayachi I, Fatima I, Wend P, Alva-Ornelas JA, Runke S, Kuenzinger WL, Silva J, Silva W, Gray JK, Lehr S, et al: The WNT10B network is associated with survival and metastases in chemoresistant triple-negative breast cancer. Cancer Res 79: 982-993, 2019

21. Gao X, Dai M, Li Q, Wang Z, Lu Y and Song Z: HMGA2 regulates lung cancer proliferation and metastasis. Thorac Cancer 8: 501-510, 2017.

22. Li XX, Di X, Cong S, Wang Y and Wang K: The role of let-7 and HMGA2 in the occurrence and development of lung cancer: A systematic review and meta-analysis. Eur Rev Med Pharmacol Sci 22: 8353-8366, 2018.

23. Xu L, Du B, Lu QJ, Fan XW, Tang K, Yang L and Liao WL: MiR-541 suppresses proliferation and invasion of squamous cell lung carcinoma cell lines via directly targeting high-mobility group AT-hook 2. Cancer Med 7: 2581-2591, 2018.

24. Mansoori B, Duijf PHG, Mohammadi A, Najafi S, Roshani E, Shanehbandi D, Hajiasgharzadeh K, Shirjang S, Ditzel HJ, Kazemi T, et al: Overexpression of HMGA2 in breast cancer promotes cell proliferation, migration, invasion and stemness. Expert Opin Ther Targets 1-11, 2020 (Epub ahead of print).

25. Sgarra R, Pegoraro S, Ros G, Penzo C, Chiefari E, Foti D, Brunetti A and Manfioletti G: High mobility group A (HMGA) proteins: Molecular instigators of breast cancer onset and progression. Biochim Biophys Acta Rev Cancer 1869: 216-229, 2018.
26. Cai X, Nie J, Chen L and Yu F: Circ_0000267 promotes gastric cancer progression via sponging MiR-503-5p and regulating HMGA2 expression. Mol Genet Genomic Med 8: e1093, 2020.

27. Li W, Li J, Mu H, Guo M and Deng H: MiR-503 suppresses cell proliferation and invasion of gastric cancer by targeting HMGA 2 and inactivating WNT signaling pathway. Cancer Cell Int 19: 164, 2019.

28. Wang $\mathrm{X}$, Wang $\mathrm{J}$ and Wu J: Emerging roles for HMGA2 in colorectal cancer. Transl Oncol 14: 100894, 2021

29. Jiang H, Li Y, Li J, Zhang X, Niu G, Chen S and Yao S: Long noncoding RNA LSINCT5 promotes endometrial carcinoma cell proliferation, cycle, and invasion by promoting the $\mathrm{Wnt} / \beta$-catenin signaling pathway via HMGA2. Ther Adv Med Oncol: Sep 29 , 2019 (Epub ahead of print). doi: 10.1177/1758835919874649.

30. Wend P, Runke S, Wend K, Anchondo B, Yesayan M, Jardon M, Hardie N, Loddenkemper C, Ulasov I, Lesniak MS, et al: WNT10B/ $\beta$-catenin signalling induces HMGA2 and proliferation in metastatic triple-negative breast cancer. EMBO Mol Med 5: 264-279, 2013

31. Shia J, Klimstra DS, Bagci P, Basturk O and Adsay NV: TNM staging of colorectal carcinoma: Issues and caveats. Semin Diagn Pathol 29: 142-153, 2012.

32. Barca I, Mignogna C, Donato G and Cristofaro MG: Expression of PLAG1, HMGA1 and HMGA2 in minor salivary glands tumours. Gland Surg 10: 1609-1617, 2021

33. Zhou Y, Huang Y, Cao X, Xu J, Zhang L, Wang J, Huang L, Huang S, Yuan L, Jia W, et al: WNT2 promotes cervical carcinoma metastasis and induction of epithelial-mesenchymal transition. PLoS One 11: e0160414, 2016.

34. Zou Y, Zhang Y, Church J and Liu X: Comparison of $\beta$-Catenin and LEF1 immunohistochemical stains in desmoid-type fibromatosis and its selected mimickers, with unexpected finding of LEF1 positivity in scars. Appl Immunohistochem Mol Morphol 26: 648-653, 2018.

35. Chen H, Gao J, Du Z, Zhang X, Yang F and Gao W: Expression of factors and key components associated with the PI3K signaling pathway in colon cancer. Oncol Lett 15: 5465-5472, 2018.

36. Zhao H, Cao Y, Wang G and Luo Z: Expression of FOXC2, PinX1, Ki-67 and Cyclin D1 in cutaneous cell carcinoma. Oncol Lett 14: 635-638, 2017.

37. Livak KJ and Schmittgen TD: Analysis of relative gene expression data using real-time quantitative PCR and the 2(-Delta Delta C(T)) method. Methods 25: 402-408, 2001.

38. Valenta T, Hausmann $\mathrm{G}$ and Basler K: The many faces and functions of $\beta$-catenin. EMBO J 31: 2714-2736, 2012.

39. Zhu J, Wang H, Xu S and Hao Y: Clinicopathological and prognostic significance of HMGA2 overexpression in gastric cancer: A meta-analysis. Oncotarget 8: 100478-100489, 2017.

40. Ma Y, Zheng W, Chen H, Shao X, Lin P, Liu X, Li X and Ye H: Glucosamine promotes chondrocyte proliferation via the Wnt/ $\beta$-catenin signaling pathway. Int J Mol Med 42: 61-70, 2018.

41. Doumpas N,LampartF, Robinson MD, Lentini A, Nestor CE, Cantù C and Basler K: TCF/LEF dependent and independent transcriptional regulation of Wnt/ $\beta$-catenin target genes. EMBO J 38: e98873, 2019.

42. Testa U, Pelosi E and Castelli G: Colorectal cancer: Genetic abnormalities, tumor progression, tumor heterogeneity, clonal evolution and tumor-initiating cells. Med Sci (Basel) 6: 31, 2018

43. Wei R, Shang Z, Leng J and Cui L: Increased expression of high-mobility group A2: A novel independent indicator of poor prognosis in patients with esophageal squamous cell carcinoma. J Cancer Res Ther 12: 1291-1297, 2016.

44. Binabaj MM, Soleimani A, Rahmani F, Avan A, Khazaei M, Fiuji H, Soleimanpour S, Ryzhikov M, Ferns GA, Bahrami A and Hassanian SM: Prognostic value of high mobility group protein A2 (HMGA2) over-expression in cancer progression. Gene 706: 131-139, 2019.

45. Yang S, Gu Y, Wang G, Hu Q, Chen S, Wang Y and Zhao M: HMGA2 regulates acute myeloid leukemia progression and sensitivity to daunorubicin via $\mathrm{Wnt} / \beta$-catenin signaling. Int J Mol Med 44: 427-436, 2019.

46. Sebio A,Kahn Mand LenzHJ: The potential of targeting Wnt/ $\beta$-catenin in colon cancer. Expert Opin Ther Targets 18: 611-615, 2014.

47. Prossomariti A, Piazzi G, Alquati C and Ricciardiello L: Are Wnt/ $\beta$-Catenin and PI3K/AKT/mTORC1 distinct pathways in colorectal cancer? Cell Mol Gastroenterol Hepatol 10: 491-506, 2020.

48. Mansoori B, Mohammadi A, Ditzel HJ, Duijf PHG, Khaze V, Gjerstorff MF and Baradaran B: HMGA2 as a critical regulator in cancer development. Genes (Basel) 12: 269, 2021.

49. Zhang S, Mo Q and Wang X: Oncological role of HMGA2 (Review). Int J Oncol 55: 775-788, 2019.

This work is licensed under a Creative Commons Attribution-NonCommercial-NoDerivatives 4.0 International (CC BY-NC-ND 4.0) License. 